\title{
"In Touch With my Creative Side": Supporting Self-Care Among Nursing Students Through Arts-Based Pedagogy.
}

Kathy O'Flynn-Magee

University of British Columbia, kathy.oflynnmagee@ubc.ca

Allie Slemon

University of British Columbia, allie.slemon@ubc.ca

Jill Mahy

University of British Columbia, jill.mahy@ubc.ca

Emily K. Jenkins

University of British Columbia, Emily.jenkins@ubc.ca

Follow this and additional works at: https://qane-afi.casn.ca/journal

Part of the Art Practice Commons, Education Commons, and the Nursing Commons

\section{Recommended Citation}

O'Flynn-Magee, Kathy; Slemon, Allie; Mahy, Jill; and Jenkins, Emily K. (2022) "'In Touch With my Creative Side": Supporting Self-Care Among Nursing Students Through Arts-Based Pedagogy.", Quality Advancement in Nursing Education - Avancées en formation infirmière: Vol. 8: Iss. 1, Article 7.

DOI: https://doi.org/10.17483/2368-6669.1300

This Article is brought to you for free and open access by Quality Advancement in Nursing Education - Avancées en formation infirmière. It has been accepted for inclusion in Quality Advancement in Nursing Education - Avancées en formation infirmière by an authorized editor of Quality Advancement in Nursing Education - Avancées en formation infirmière. 


\section{"In Touch With my Creative Side": Supporting Self-Care Among Nursing Students Through Arts-Based Pedagogy.}

\section{Cover Page Footnote}

We thank student participants whose perspectives and creative assignments were invaluable in the completion of this work. Nous remercions les étudiantes participantes, dont les perspectives et travaux créatifs ont grandement contribué à la réalisation de ce texte. 


\section{Introduction}

The importance of students' active engagement in their learning has never been timelier given the complexity of current nursing practice and education (Nguyen et al., 2016). Learners must be committed, and nurse educators must have the pedagogical competency to draw on a diverse range of teaching and learning strategies to capture learners' attention and ensure they are motivated and excited to learn. Arts-based pedagogy (ABP) offers many choices within its genre and is a creative option for educators to consider for engaging students in learning.

The qualitative findings described in this paper are part of a mixed method study that explored nursing students' perspectives on a creative arts-based assignment designed to support their self-care. The purpose of the study was to assess the impact of the assignment on nursing students' management of stressors (both personal and program related) and on their well-being throughout and following the completion of the assignment. In an earlier publication, we focused on the quantitative findings regarding the impacts of the assignment on self-care practices (Jenkins et al., 2019). In this paper, we concentrate on the creative, arts-based aspect of the self-care assignment, presenting qualitative findings from open-ended survey questions and images from students' submitted work. These illustrative examples provide insights into the positive impacts of an ABP approach for students, as well as the related challenges. We further share our own reflections on the creative aspect of the assignment, with guidance for other nursing educators to integrate ABP approaches into nursing education.

\section{Background}

\section{Literature Review}

Although the term $A B P$ is seldom located in nursing literature, its essence is captured in the many descriptions of learning activities that draw on the arts (Rieger \& Chernomas, 2013). Based on their concept analysis, Rieger and Chernomas (2013) defined ABP as a creative approach that uses the arts to foster learning about a topic or field of study. The authors described three critical attributes of $\mathrm{ABP}$ :

1) a time and setting in which the active learning experience occurs; 2) learning is designed to occur through the use of one or more art form(s) integrated with a subject matter from another academic discipline; and 3) active learner participation in the artistic process and/or reflective observation of an art form. (p. 6)

$\mathrm{ABP}$ has been used in undergraduate nursing education in two ways: as a form of learning and as a form of assessment. Our review of the literature uncovered numerous examples of the use of the arts as a way of supporting learning in educational contexts. Over 25 years ago, Darbyshire (1994) bemoaned the lack of arts and humanities in nursing education. To describe nursing as "an art and a science" was, Darbyshire believed, a cliché waiting to happen unless the arts and humanities became more valued and less marginalized in nursing education. More recently, Rolfe (2014) argued for a return to a liberal education for nurses-including exposure to courses in the humanities, arts, classics, and philosophy — so that they can learn to truly bear witness and respond to another's suffering. ABP can foster sociopolitical and emotional learning and can result in deeper and truly transformative learning for students (MacDonnell \& Macdonald, 2011; Rieger et al., 2020a). In studies examining the impacts of ABP approaches in nursing education, ABP has been shown to foster students' critical thinking, nursing assessment and diagnosis, interpersonal skills, and personal creativity (Casey, 2009; Elhammoumi \& Kellam, 2017). Indeed, McGarry and 
Aubeeluck (2013) drew on ABP in a project that involved the co-creation of a theatre-based workshop that supported nursing students' understanding of complex concepts, such as living with communication challenges, stigma, and social exclusion. In McGarry and Aubeeluck's project, students worked with individuals who lived with learning disabilities to co-create works of art. Evaluation of the project revealed that this type of non-traditional pedagogy may be ideally suited for learning related to the nuanced and complex topics that are commonplace in nursing. Emmanuel (2016), using ABP as a form of assessment, similarly found that it can support students in reflecting on stigma and discrimination. The author created an assignment whereby students were asked to envision a day in the life of a person with a mental health condition and to capture that imagined experience through artistic expression. The exercise pushed students to confront their prejudices about mental health/illness, and, for some, it reduced their anxiety about caring for clients with mental illnesses (Emmanuel, 2016). It is clear that ABP has many benefits, especially for nursing students, given the complex roles they take on within a program of study in nursing.

\section{Conceptual Framework}

The framework was informed by the concept of creativity, which guided the self-care assignment we discuss in this paper. Creativity can be defined as "the process of developing something unique that is of value" (Robinson, 2017, Rethinking Creativity section, para. 1). It can be seamlessly fostered within ABP because the latter embraces creativity as its core structure (Rieger \& Chernomas, 2013). We were interested in giving students the opportunity to engage in creativity of any form within an ABP approach to explore and learn about their own stressors and self-care practices.

Robinson's (2006) question “Are schools killing creativity?" was important because one of our goals was to provide students with a rare opportunity to be creative in a higher education nursing context, which seldom makes space for this approach to learning (Duhamel, 2016; Rieger et al., 2020b). Creativity within ABP (CwABP) was woven into the design of the assignment, and it guided our analysis of how students experienced and valued engaging in a creative arts-based self-care assignment.

\section{Methods}

\section{The Assignment}

As a group of nursing faculty and one doctoral student from a research-intensive university in Western Canada, our experiences as mental health practitioners, teachers, and researchers have sensitized us to the numerous stressors experienced by pre-licensure nursing students, as well as alerting us to the potential of creative arts-based approaches to integrating self-care into the classroom. Previously, Jenkins designed a graded assignment that focused on how students could manage their identified stressors through self-care activities. The remaining authors of this paper have integrated the assignment into multiple courses within a 20-month accelerated bachelor of science in nursing (BSN) degree program for third- and fourth-year undergraduate students. The assignment requires students to engage in and reflect on self-care activities of their choosing that they identify as helpful in alleviating stressors. Additionally, it provides an opportunity for students to examine and present scholarly evidence for their selected self-care activities. With the goal of emphasizing relevant core course concepts, the assignment contributes to pedagogical linkages between self-care, stress, students' mental health (Jenkins et al., 2019), and fitness to practise (BC College of Nurses and Midwives, 2018). We provide a detailed description of the assignment and 
results from a quantitative survey analysis of the impact of the assignment on students' capacity for self-care in a separate manuscript (Jenkins et al., 2019). In this paper, we focus primarily on the pedagogy used (CwABP) to support students' self-care practices.

\section{Recruitment and Data Collection}

To examine students' experiences of and perspectives on a creative ABP approach to education on self-care, we conducted a survey containing both closed- and open-ended questions among two cohorts of BSN students who had recently completed the assignment during their coursework. The survey used for this study consisted of 13 closed-ended questions, with results from these quantitative data reported elsewhere (Jenkins et al., 2019). It also included three openended questions, the data from which are the focus of this paper:

1. Please describe the ways in which this assignment was meaningful to you.

2. Please describe any challenges you encountered in completing this assignment.

3. What could be done in the nursing program to help support your ongoing commitment to self-care?

Survey data were collected from January to March 2018, and all students recruited to the survey had completed the assignment within the previous year. Fourth-year students had completed a creative format of the assignment in a mental health course, and third-year students had self-selected a creative or paper-based format of the assignment in an introductory foundations of nursing course. Students were recruited to participate in this study through an email sent to all BSN students, as well as through flyers and in-class announcements. Class time was dedicated for students to voluntarily complete the survey; this was facilitated by course instructors, and members of the research team were not present during data collection. Ethics approval for the study was obtained through the University Behavioural Research Ethics Board. Participants were given the option to enter into one of two draws for a $\$ 50$ gift card to acknowledge their contributions.

Students were also invited to optionally submit copies of their self-care assignments by emailing electronic versions or photographs to the research team contact or lending the original assignment to the research team for photographing. All hard copies of assignments were stored in a locked cabinet in the primary author's workspace, and electronic copies were encrypted and stored on a secure server hosted by the authors' institution. They were stored separately from survey responses to protect participant confidentiality. All images presented below are used with the permission of the students who created the assignments depicted.

In total, $89 \mathrm{BSN}$ students completed the survey, and 13 submitted copies of their self-care assignment as data for this study. Of the total sample, 57 (64\%) completed the assignment in the first-year foundations course, and $32(36 \%)$ completed the assignment in the upper-year mental health course. Fifty participants $(56 \%)$ completed the ABP-based version of the assignment (including all students who completed the assignment in their mental health course), and the remainder completed the formal paper version. Of the total sample, 78 (88\%) participants identified as female, $8(9 \%)$ identified as male, and $3(3 \%)$ identified as genderqueer. Most students (69 or $78 \%$ ) had previously completed an undergraduate or college degree before beginning the BSN program, $12(13 \%)$ had completed a graduate degree, and $8(9 \%)$ had completed a partial degree. Twelve participants (13\%) were under 23 years of age, $54(61 \%)$ were 23 to 27, 19 (21\%) were 28 to $33,3(3 \%)$ were 34 to 39 , and $1(1 \%)$ was $45+$. 


\section{Data Analysis}

Informed by interpretive practices of qualitative research, data were analyzed thematically to examine the experiences, impacts, and challenges of a CwABP assignment on students' selfcare (Braun \& Clarke, 2006; Braun et al., 2019). We specifically approached data analysis through Braun and Clarke's (2019) guidance on undertaking reflexive thematic analysis, which supports rigorous analytical processes but also acknowledges the "fluid and recursive" nature of theme development (p. 591). To facilitate analysis, all survey data from open-ended responses were uploaded to Microsoft Word. First, data were read through in an iterative process among members of the research team to identify salient elements of participants' experiences and perspectives. Second, these elements were then developed into themes through discussions among the research team and deep reading of the data to identify "patterns of shared meaning organized around a core concept" (Braun et al., 2019, p. 845). Third, the text and images of assignment submissions were read alongside qualitative survey data to further nuance the themes generated through this analytic process. These data serve as illustrative examples of the experiences of a creative ABP approach for students, as well as the challenges associated with such projects. We further share our own reflections on the creative aspect of the assignment, with guidance for other nursing educators in integrating $\mathrm{CwABP}$ approaches into nursing education.

\section{Findings}

Thematic analysis of qualitative survey responses and the content of students' self-care assignments resulted in the generation of three broad themes: (a) Academic Stress and Moral Distress, (b) Legitimizing CwABP and Self-Care, (c) Intentions and Tensions. First, we identify the academic and moral stressors experienced by students as context for their engagement in selfcare practices through the assignment. Next, we examine how the assignment legitimized a $\mathrm{Cw} \mathrm{ABP}$ approach as an education strategy. We also explore how the use of a CwABP legitimized the assignment as a way to support self-care as a practice for students and build their capacity for self-care. Finally, we reflect on the theme of Intentions and Tensions to explore some of the challenges of the assignment, in particular the integration of scholarly literature into a creative assignment, and the grading of the assignment. Throughout our exploration of these themes, we situate participants' reflections on the self-care assignment in our experiences as educators delivering and evaluating the assignment.

\section{Academic Stress and Moral Distress}

In completing the assignment, students were required to identify their stressors as a first step in preparing to more intentionally manage them through selected self-care activities. It was clear that participants experienced numerous stressors in their everyday lives as nursing students.

See Figures 1 to 4 for students' visual representations of stressors experienced in nursing school. 


\section{Figure 1}

\section{Stressors}

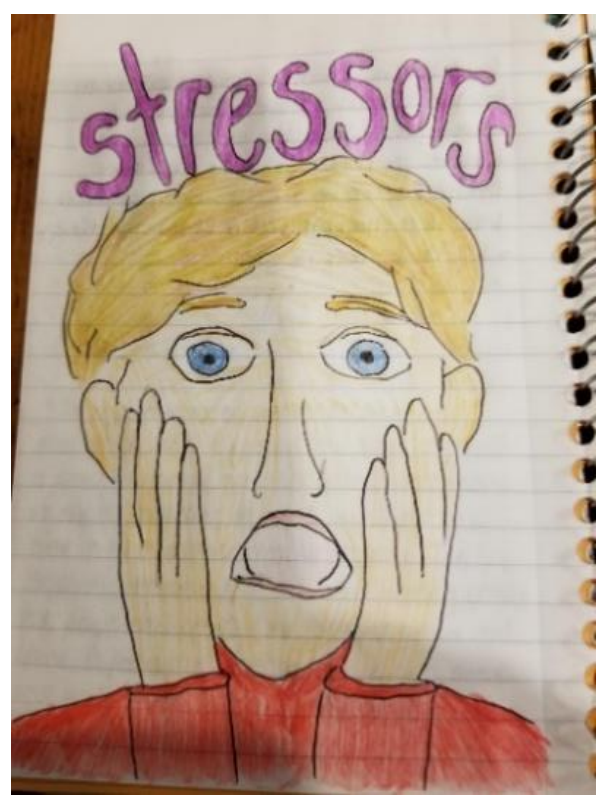

Used with permission.

\section{Figure 2}

"A key component of any self care reflection is to first recognize the stressors that can lead to burnout."

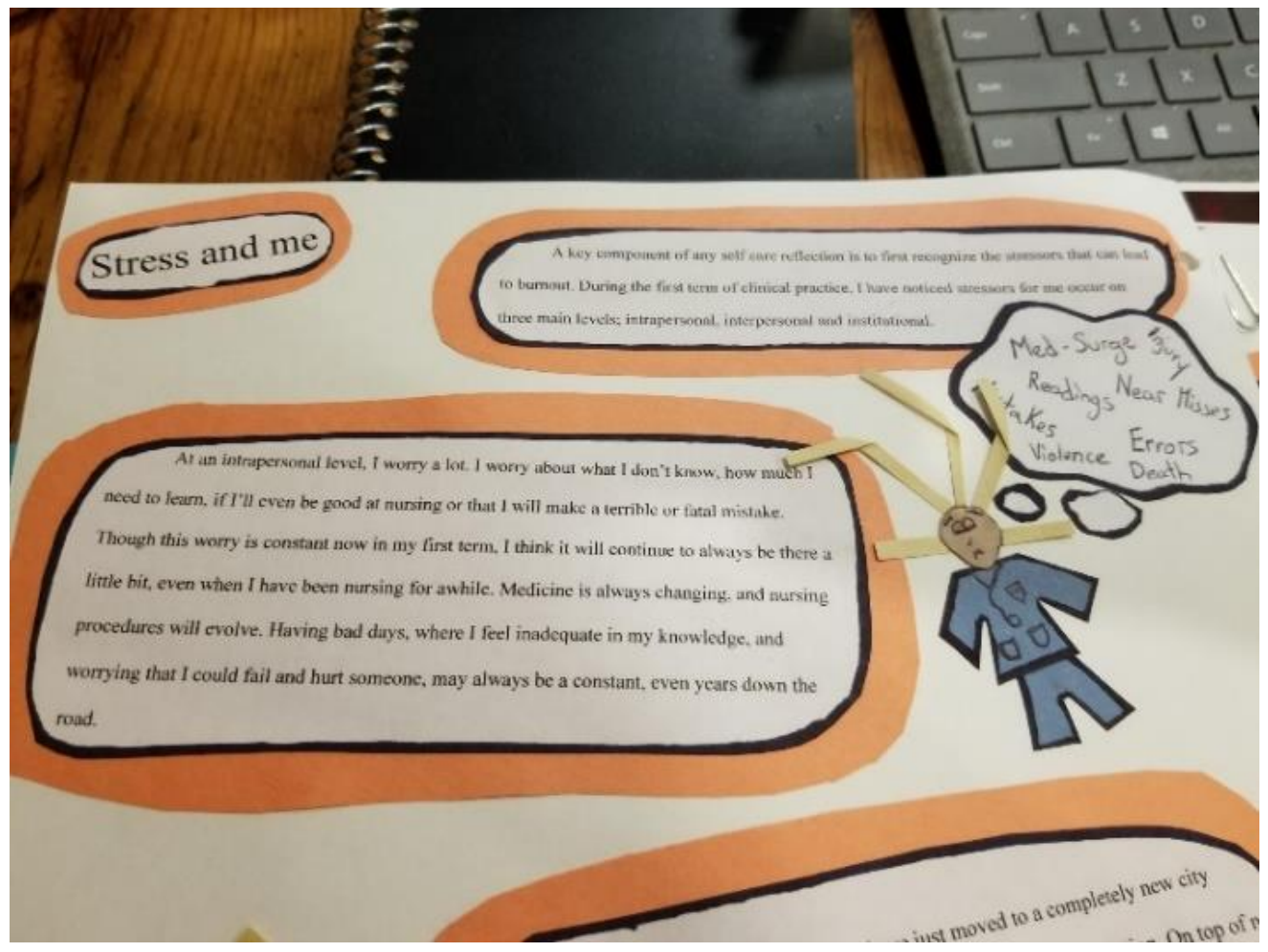

Used with permission. 


\section{Figure 3}

"Change, Overstimulation, Loneliness, and Depression"

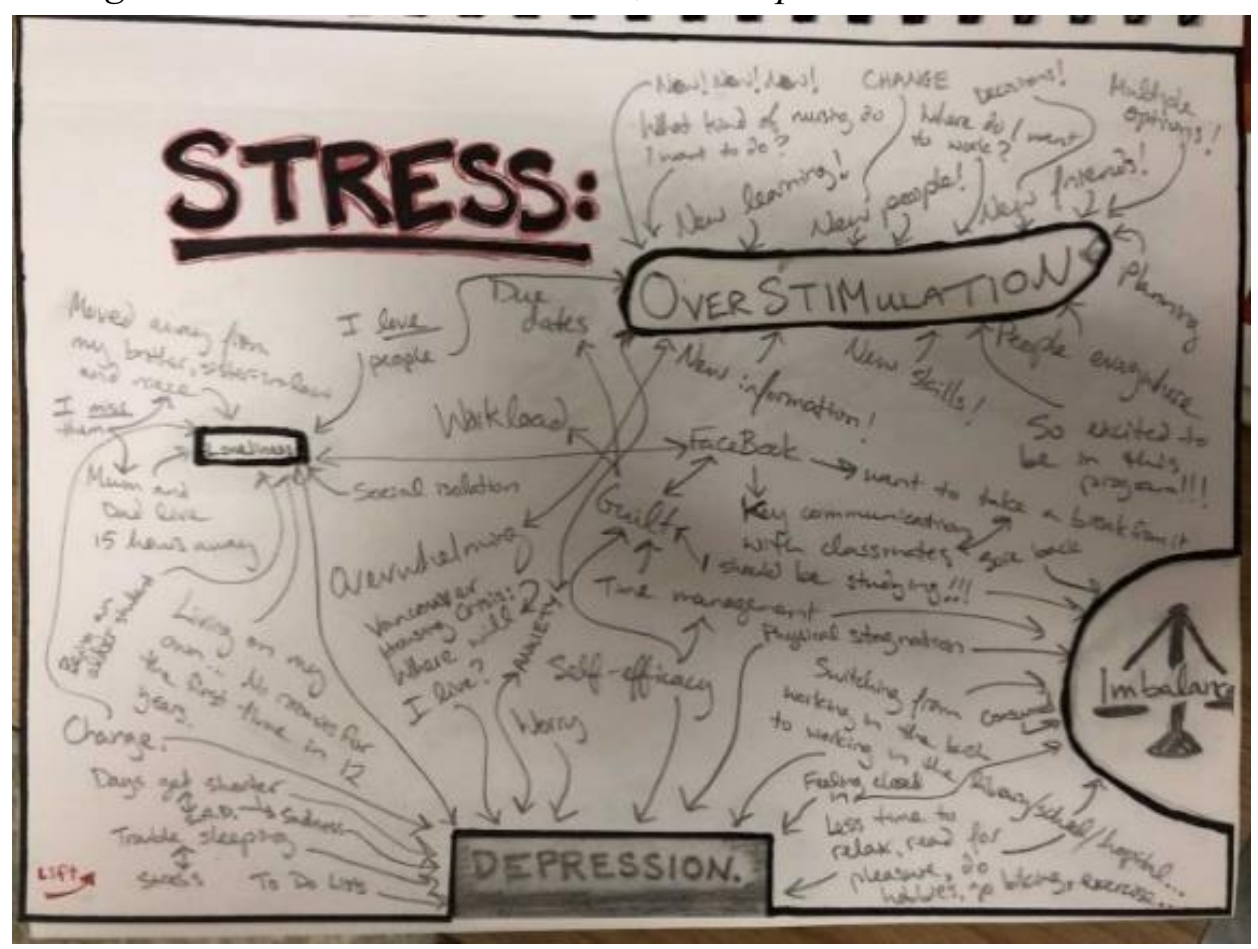

Used with permission.

\section{Figure 4}

\section{Workload!}

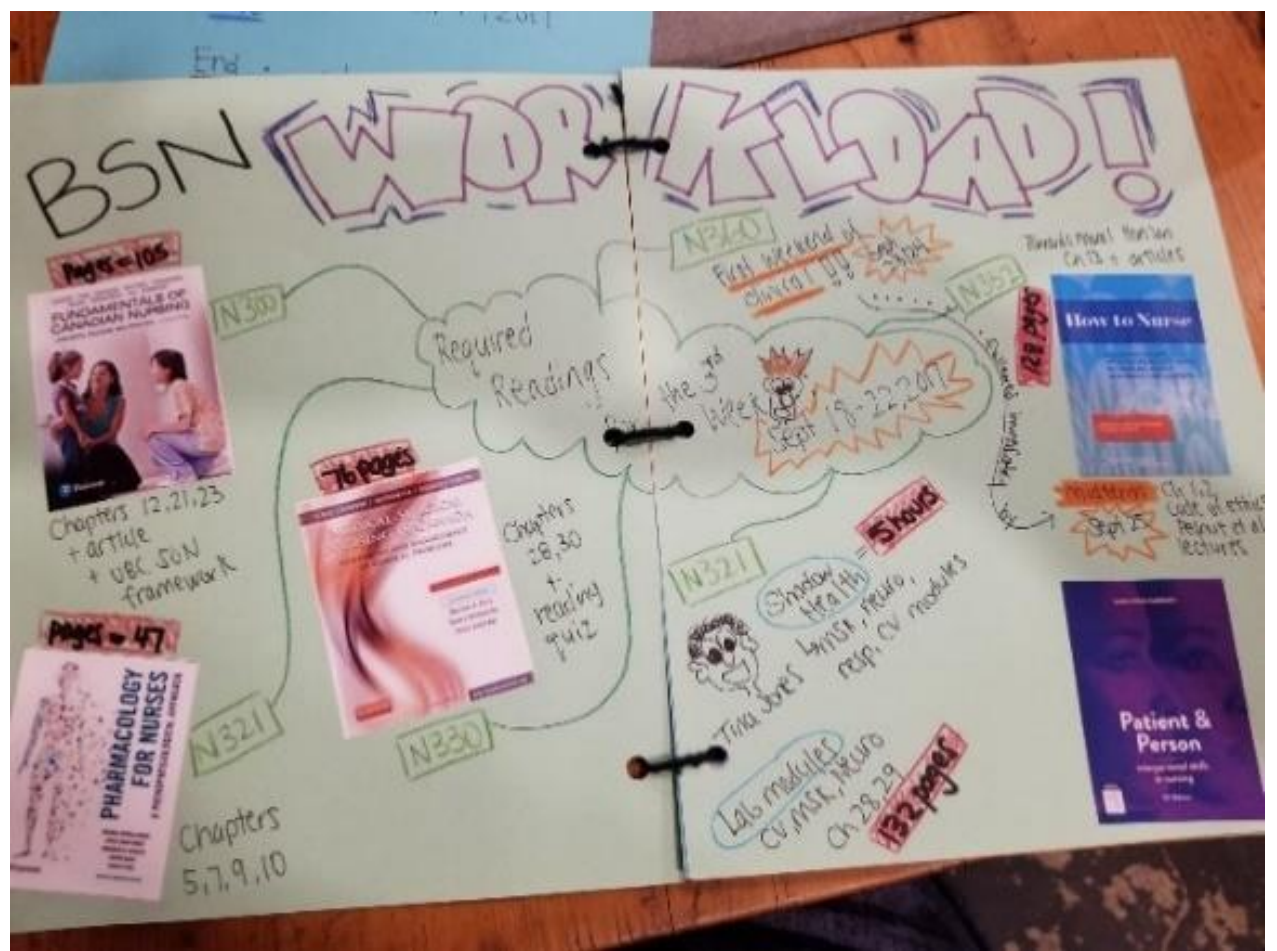

Used with permission. 
Additionally, for students in our study, stressors specific to nursing school surfaced. In particular, clinical practice stood out as a unique stressor that nursing students faced. Participants described clinical practice as a place that can be "daunting, emotionally taxing and physically demanding," and "where stress, anxiety and moral distress can occur on a daily basis." As one participant shared, "I have experienced a new form of stress, 'moral distress' in the clinical setting when having to prioritize educational experiences in relation to patients' preference for a 'quick and easy' assessment or the other nurse's efficiency." This participant thoughtfully recognized that prioritizing student learning over patient preference or nurses' efficiency in managing their workload can be morally challenging. Students also anticipated future stressors related to clinical practice and post-licensure nursing practice, such as witnessing end of life, giving upsetting or distressing news to families, or the "inescapable feeling of not having done enough or not being enough for patients or team members in the clinical setting." These stressors can weigh heavily on students, making it especially important for nurse educators to be aware of what students may be experiencing so that they can help them to anticipate previously unknown stressors, normalize their existence, and support students when they do experience them. As voiced by one participant:

I believe great personal power exists in being able to recognize our own signals of morale [sic] distress and I am hopeful that through ongoing reflective action, I can navigate my emotions for continued insight and freedom from negative thought patterns, allowing me to be the best version of myself in the workplace.

\section{Legitimizing CwABP and Self-Care}

There were a number of ways in which the assignment legitimized self-care as an important practice for nursing students, and in so doing, the process ( $\mathrm{CwABP}$ ) was also legitimized. Assigning a creative arts-based project was, in itself, a way in which CwABP was valued. Giving university credit (in the form of a partial course grade) for the completed assignment and providing students with academic time to immerse themselves in a creative space also illustrated the valuing of the creative $\mathrm{ABP}$ process as a way to engage in self-care. The requirement for students to actively engage in forms of self-care further acknowledged it as a legitimate and valuable practice. Finally, linking the assignment to core course concepts such as fitness to practise provided legitimacy and supported student's understanding of how self-care is an imperative for students to practise safely.

One of our goals in offering the assignment was to encourage students to use self-care as a way to manage their stressors and to invite a creative approach in the hopes that, unlike most assignments, which can invoke a sense of stress during the completion process, the doing of this assignment could itself reduce or mitigate the impacts of stressors (see Figure 5). 


\section{Figure 5}

A still image from a student video depicting knitting as a new self-care practice illustrates that completing the assignment was itself a form of self-care.

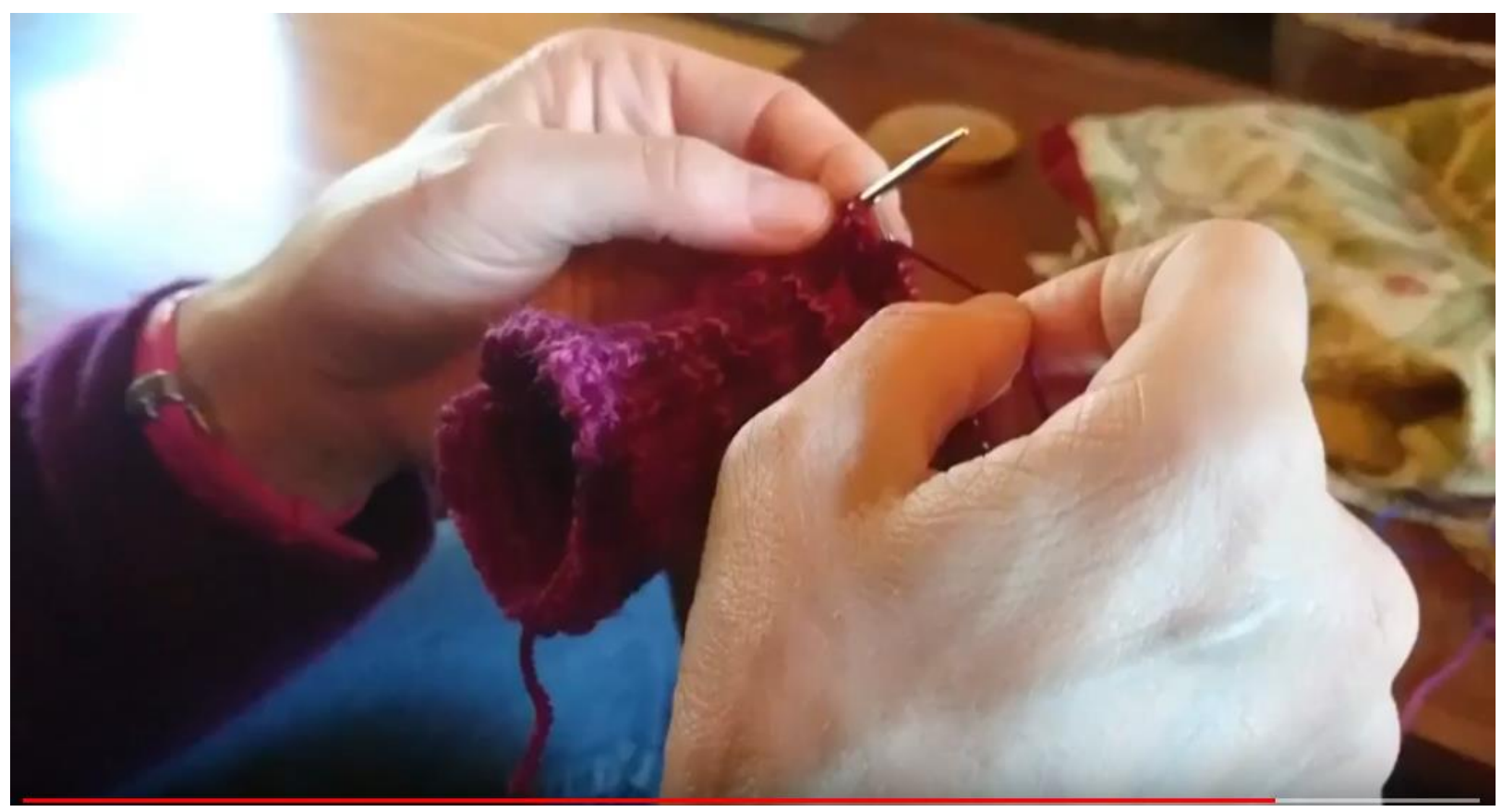

Used with permission.

We also believed that gaining course credit for engaging in self-care would be a wonderful bonus because the process facilitated immersion in self-care within a course rather than as something necessitating additional time beyond required course and clinical requirements. One participant explained that they genuinely enjoyed "being able to do a creative component. I don't find a lot of time with classes/clinical to be in touch with my creative side, and it was great to be able to do so for an academic assignment." Another participant similarly reflected on the benefits of the assignment for promoting self-care, voicing that the assignment "made me identify my stressors and investigate ways to manage [them]. The assignment was really meaningful in the way it made me become more aware of myself. I learned a lot about myself." Participants reflected on the benefits they derived from engaging in their chosen self-care strategies. One student shared that her "worries seem[ed] to fade away in the quiet [space of diving]" (Figure 6). 


\section{Figure 6}

Diving: "Underwater is truly a space where my worries no longer hold any weight."

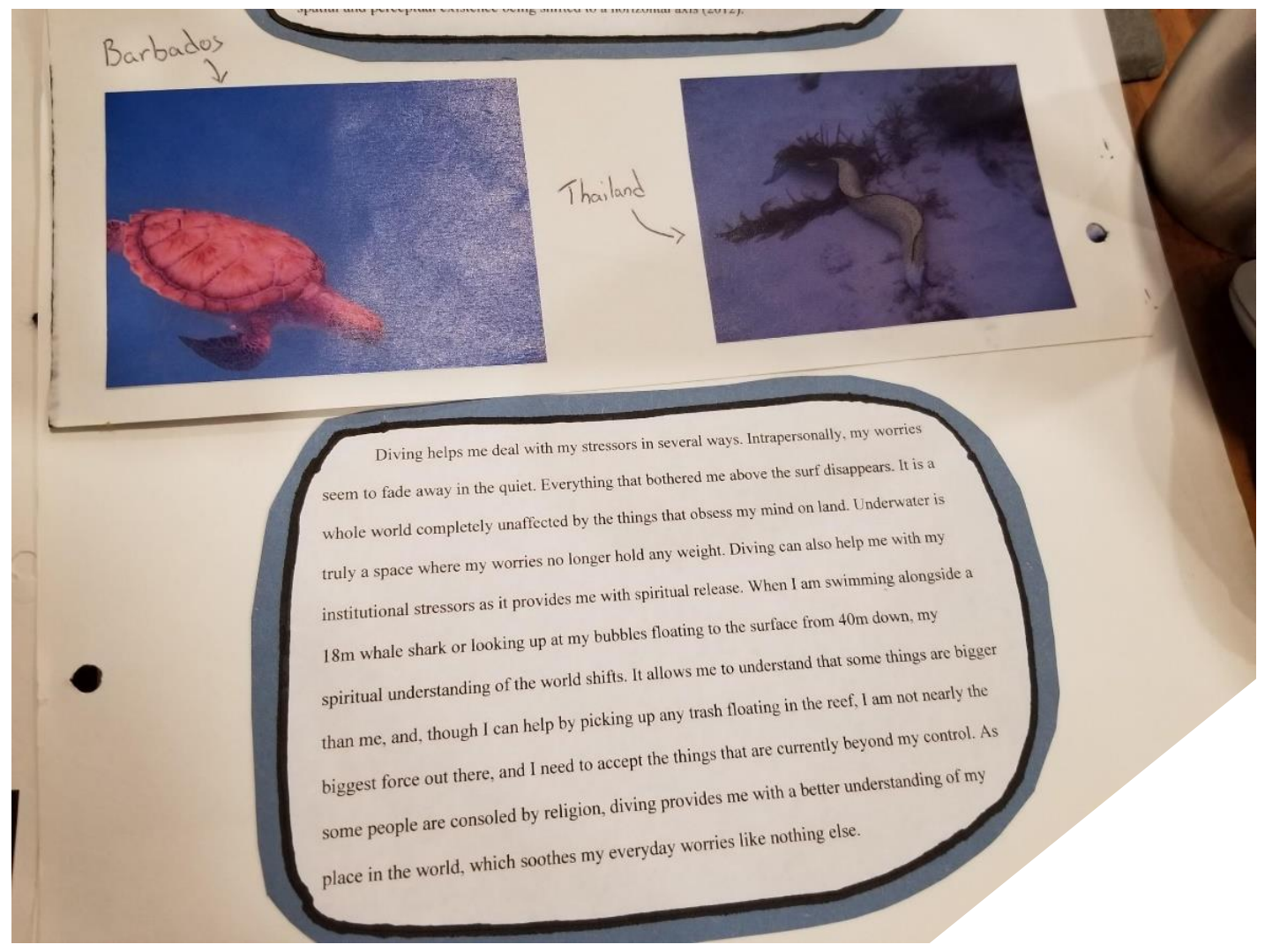

Used with permission.

Similarly, another participant talked about the benefits of being in nature as a self-care practice: "Being outside has a way of reminding me of the stillness that always exists despite the stressors we experience in any given moment."

Linking the self-care assignment to the core course concepts of fitness to practise and students' well-being was imperative because it allowed students to more clearly understand the assignment's purpose and enhanced their capacity to see important benefits. In so doing, it legitimized self-care as a practice for nursing students. As illustrated by one participant, "overall I feel that self-care is one of the most important parts of my fitness to practice as a nurse," while another participant was "struck by the concept of self-care to prevent health care practitioner burnout, and to promote ongoing compassion toward others." Self-care was consistently linked to students' personal well-being and fitness to practise; interestingly, student perspectives illustrated that the assignment was not only helpful at an individual level but also beneficial within the broader group of students. As described by one participant:

[the assignment created] a culture of self-care in the cohort. People joked about dinner parties being self-care or sports activities or potting classes. This normalization of self-care is firmly established in the students and has greatly increased awareness of how important self-care is to our fitness to practice. 
This approach fostered a sense of camaraderie in the classroom, and it was lovely for faculty members to overhear the various lighthearted references to self-care, most often following the weekend. Further, the graded structure of the assignment provided students with a certain validity and justification to spend time immersed in self-care activities and artistic expression. As described by one student, "It helped me justify or legitimize the practice of self-care when I was feeling stressed about getting enough studying and work done for school." Using a creative approach to examining course content on self-care and fitness to practise was identified as enhancing students' learning about stress, fitness to practise, and self-care as important issues. As described by one participant in our study:

I have tried meditation several times now, and absolutely adored it. However, until this assignment, I had not ever consciously thought to make a habit of continuing to practice it alone at home. For the purpose of this assignment, I created a schedule which included the practice of meditation on Monday, Wednesday and Friday mornings for 15 minutes. I began this practice in mid-September and hope to continue with it as a consistent habit.

This quote illustrates how the assignment helped one student to recognize the importance of selfcare and to make a conscious choice to integrate it into their everyday life. Not only was there learning within the assessment but also beyond it. The learning embedded in meditation is mirrored by another participant who describes how the strategy taught them to be patient as well as helping them to be mindful about their thoughts (see Figure 7).

\section{Figure 7}

Learning from Self-Care: "It really has done wonders for me already and I am grateful I had the opportunity (or the assignment) to try something new like this."

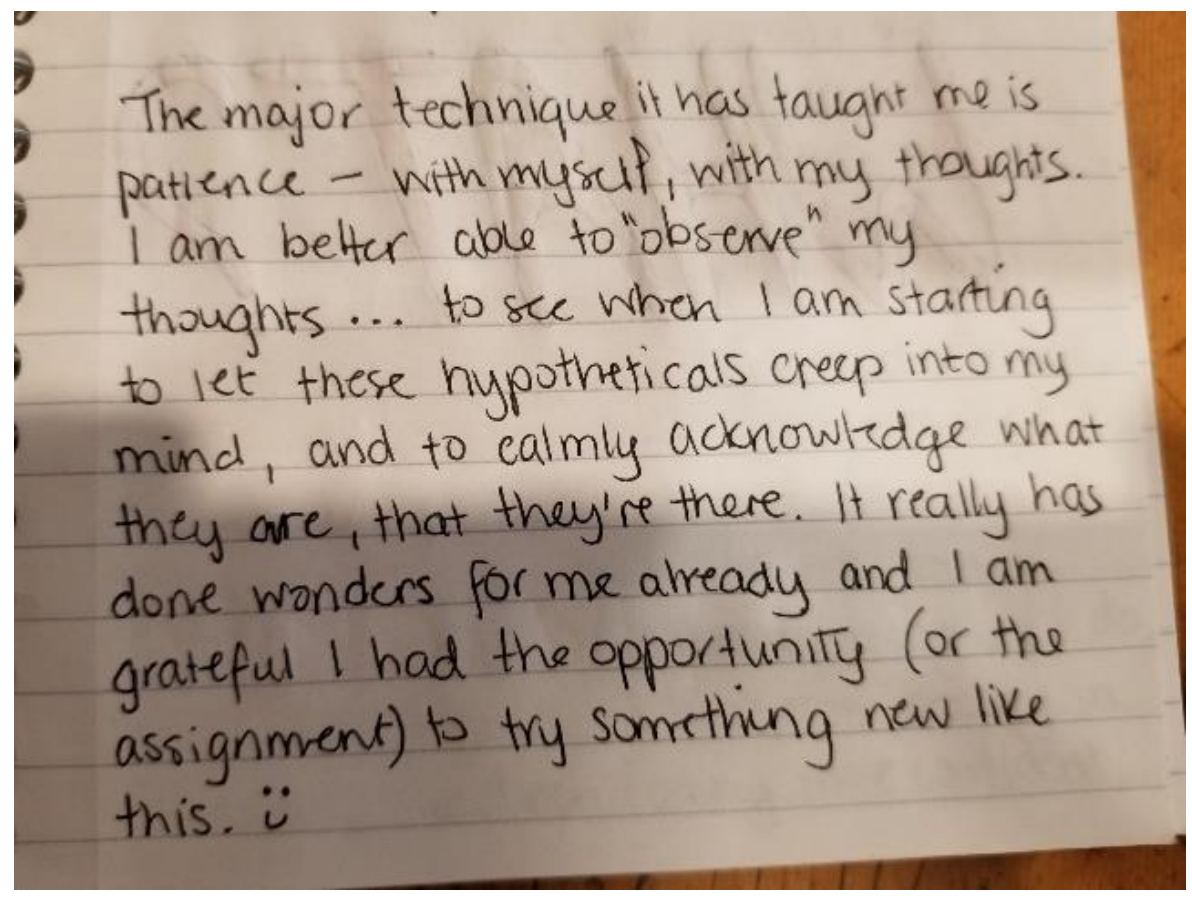

Used with permission. 
Legitimizing self-care through a CwABP allowed participants to value the opportunity to immerse themselves in aesthetic aspects of nursing. For example, one student described how "this assignment allowed me to fully express myself." Another participant commented that "taking time to create and consume art in different forms feeds my intellectual, emotional, and spiritual health" (see Figure 8).

\section{Figure 8}

A student uses a diagram and reflective commentary to convey the need for balance between physical, emotional, spiritual, and intellectual health and suggests pottery as a new creative pursuit to rebalance these spheres in the context of nursing school stressors.

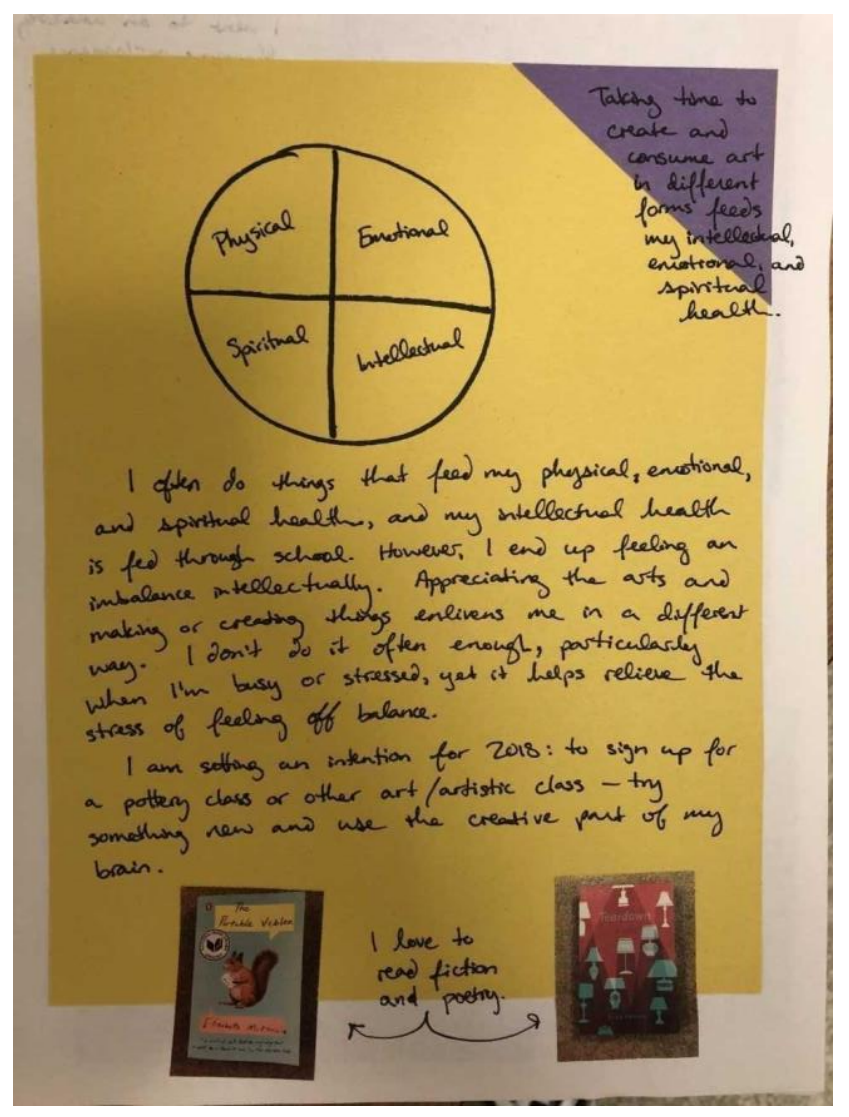

Used with permission.

As well as sharing the various stressors that they were experiencing, participants also shared many of the self-care strategies they chose to mitigate those stressors (see Figures 9 to 11). 


\section{Figure 9}

Staying Active

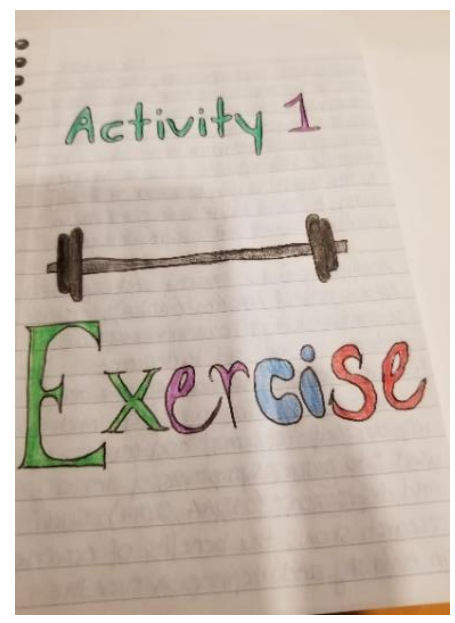

Used with permission.

\section{Figure 10}

\section{Healthy Eating}

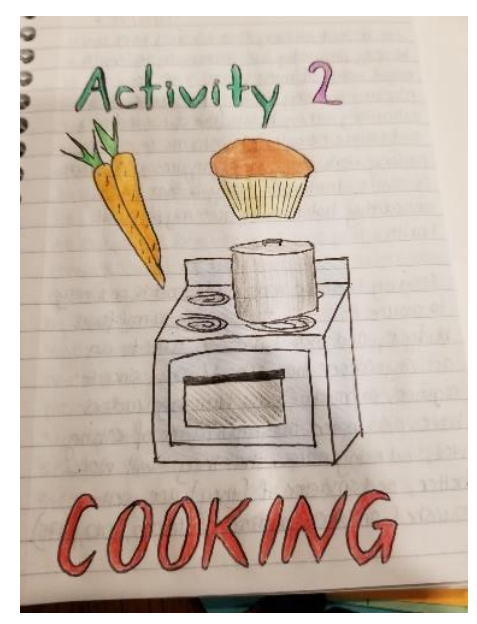

Used with permission.

\section{Figure 11}

Sleep

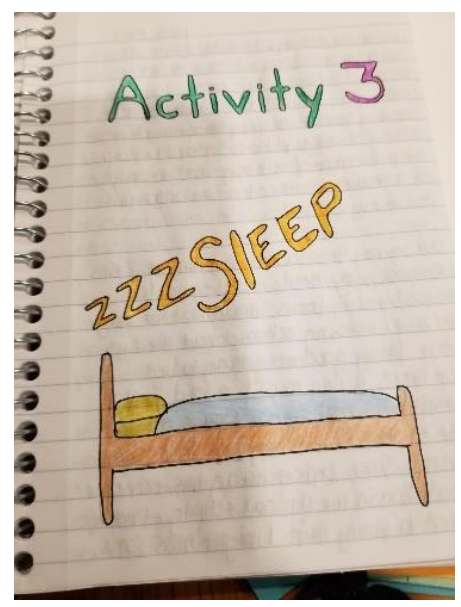

Used with permission.

Legitimization can support students' self-care during nursing education and into future nursing practice as they continue to encounter stressors in clinical practice (see Figure 12). 


\section{Figure 12}

Linking Self-Care to Patient Care: "I'll be stressed, I'll be angry, and I'll be sad, and I'll know why. I need to remember that providing care is useless if I do not care for myself. Just as it is unsafe to work when sick, it is equally unsafe to work when emotionally or spiritually depleted, and so, in the end, self-care equals good care."

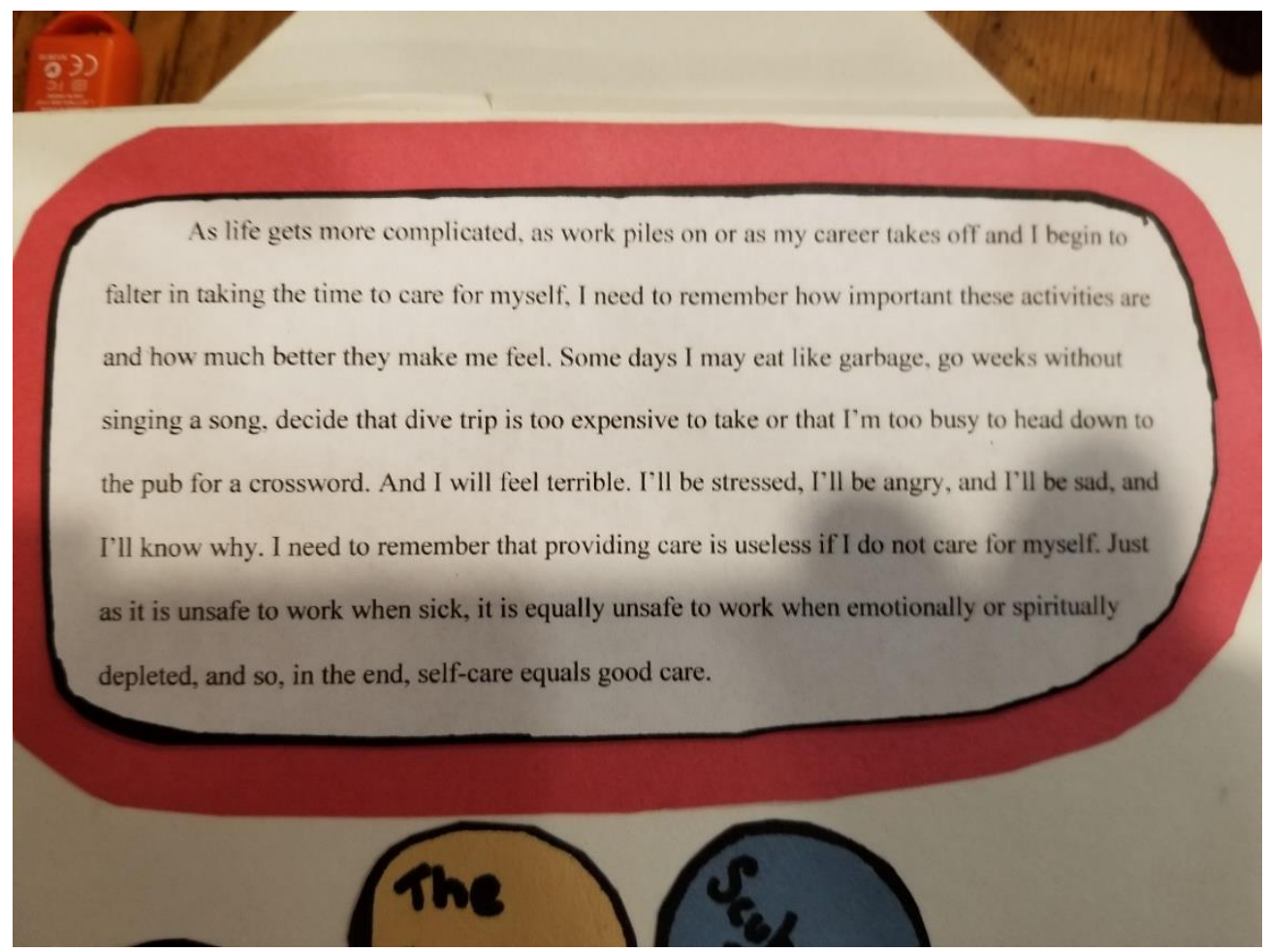

Used with permission.

\section{Intentions and Tensions}

Not surprisingly, ABP may not be for everyone; some teachers may never use it and some students may resist engaging in it. As always, it is crucial to explore varying perspectives to make the best evidence-informed decisions in nursing education. While the authors' intentions were for students to complete an assignment that was evidence based and graded fairly, tensions arose in these two aspects of the assignment. Although many participants in our study greatly enjoyed the creative component, some wished they were not required to provide scholarly evidence for their chosen strategies, which was viewed as a detractor from the creative process. As stated by one participant, "It would have been helpful to be able to not provide scientific support for some of the activities I partake in, and rather provide a reflective summary of how I believe it works in managing my stressors."

This participant was not alone, and another voiced similar concerns:

I didn't find it useful to have the research component tied into the assignment. I truly enjoyed the self-care and creative component, so it was frustrating to then have to tie in a paper and research to receive marks. It felt forced and like it took away from the fundamental principle of the assignment. 
Although a small number of participants struggled with integrating scholarly evidence, we as educators saw substantial benefit in asking students to explore the literature for evidence to support their chosen strategy for their specific stressor. We believed it was more robust and had the potential to introduce students to the evidence underlying their practices, as illustrated in the following participant's perspective:

This assignment really opened my eyes to how much of an impact self-care can have in times when there is a lot of stress in my life. Nursing will bring on physical, mental and emotional challenges and I learned there is an evidence base that backs up the need for self-care in order to be able to handle those challenges well. I also enjoyed having to try a new self-care activity, and I actually still practice it now!

Figure 13 further illustrates one student's appreciation for the evidence underlying sleep as a selfcare practice.

\section{Figure 13}

\section{Sharing the Evidence That Sleep Is an Important Self-Care Practice}

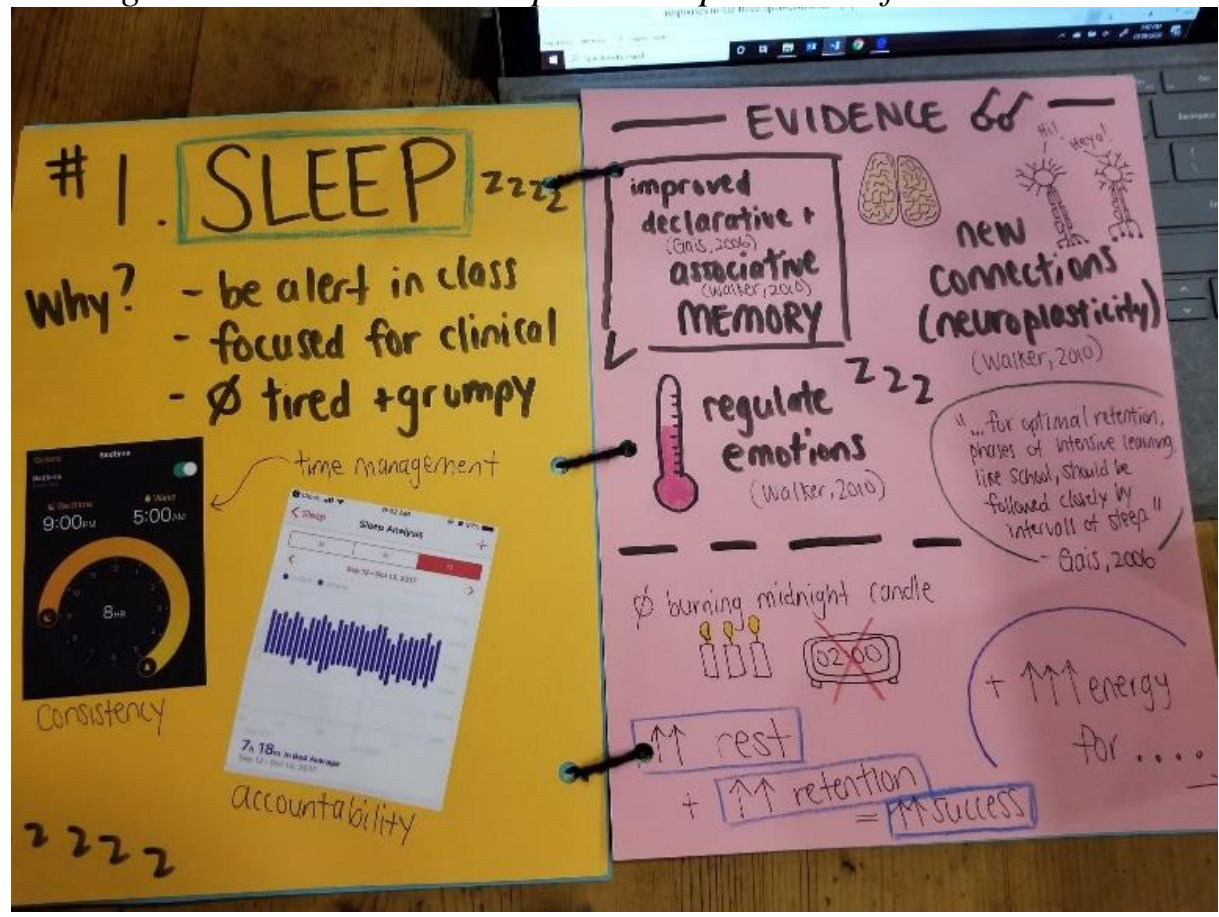

Used with permission.

For faculty members and students involved in this assignment, grading and being graded brought its own set of challenges. For example, although there was grading consistency within courses, this was not necessarily the case across courses. Assignments in some courses were graded according to evaluative criteria, whereas in other courses the assignment was graded as a participatory activity and completion of the assignment resulted in the full grade. While this process was not problematic because it was across and not within courses, it highlighted some challenges that those grading with criteria experienced. From some participant perspectives, the creative assignments were "graded more harshly than solely written ones, or at least it was expected that the creative projects also had a written component... This made it a lot of work. It was kind of stressful actually." As one participant suggested, "Either make everybody do the paper 
and assess the quality of the paper or allow a completely creative approach. The discrepancy that resulted from the two different approaches made it hard to assess the quality of self-care." In suggesting that the aim of grading was to "assess the quality of self-care," this student raises the importance of clarity in the processes of rubric development and grading. To reduce students' stress related to evaluation, educators can - and should - differentiate between grading substantive components of the assignment itself and grading students' enacted self-care practices (see the Appendix for the assignment instructions).

\section{Discussion}

Higher education provides opportunities for significant personal and professional growth; however, it can also contribute to high levels of stress and distress for many. Our study illustrates that nursing students face many stressors during their programs of study, including heavy classroom and clinical workloads, stress associated with assessments and evaluations, and worry about their competencies as health care providers. A creative arts-based assignment focused on self-care can support students in coping with these various stressors, through legitimizing self-care practices and offering a creative outlet for students to explore their own experiences with stress and self-care. However, findings from this analysis also illustrate that despite the best intentions of educators, there are enduring tensions surrounding a creative self-care assignment, most notably related to successful integration of $\mathrm{CwABP}$ approaches into nursing education and in regards to grading.

\section{Interpretation of Findings Within Existing Literature}

Findings from this study corroborate a considerable body of literature that demonstrates the multitude of stressors experienced by students in higher education (Acharya et al., 2018; Seaward, 2018). Wrench et al. (2013) explored first-year health science students' experiences of health and well-being during transition to university and found that for some participants, "the experience was one of alienation, isolation, and feeling disconnected" (p. 737). In addition to general stressors experienced across higher education programs, nursing students such as participants in our study face moral distress on an ongoing basis (Fischer \& Kiernan, 2019; Milligan et al., 2017). Drawing on the work of American ethicist Andrew Jamenton, Rodney et al. (2013) described moral distress as "what nurses (and other moral agents) experience when they are constrained from moving from moral choice to moral action - an experience associated with feelings of anger, frustration, guilt and powerlessness" (p. 169). Situations that are particularly stressful for students are those that infringe on the quality of patient care, and uncertainty of how to respond compounds experiences of moral distress (Sinclair et al., 2016).

Participants in our study valued the opportunity to immerse themselves in what Chinn (1994) and Purnell (2016) described as the "aesthetic aspects" of nursing. Identified in the literature are many benefits of using the arts as a pedagogy, which echo our participants' experiences of completing a creative self-care assignment. For example, Lutter et al., (2018) used ABP with students during clinical post-conference, and they discovered that rather than feeling "grilled" at the end of a busy shift, students experienced ABP approaches as stress relieving, engaging, and informative. Their study findings revealed that through engaging in ABP, students developed new viewpoints about nursing, a greater awareness of the patient experience, stronger understanding of themselves and their peers, and an appreciation of the arts to foster learning and reflection. Other benefits of ABP identified in the literature included the enhancement of students' skills, increased comfort working with specific client groups, a greater understanding of complex 
concepts, a stronger awareness of the client experience, a push to confront one's own prejudices, and an appreciation of the arts to foster learning and reflection (Emmanuel, 2016; Lutter et al., 2018; McGarry \& Aubeeluck, 2013).

Despite the many benefits of ABP, our analysis identified that students also experienced particular challenges in undertaking this creative assignment, which other research on creative pedagogy has likewise demonstrated. For students, arts-based learning and assessments can seem daunting because they are required to engage in learning and assessment at both the scientific and the aesthetic levels (Pavill, 2011; Rieger et al., 2020b). For some students, rather than feeling daunted, they may perceive ABP as "frivolous," and, as noted by Pavill (2011), they may resent the time taken away from their valued technical skill development or lack confidence in their perceived ability to be creative. Resistance to ABP may exist at varying levels and for varying reasons. From the perspective of educators and administrators, challenges associated with using ABP include the need for students and teachers to be comfortable with ambiguity and a shift in structure and direction (Casey, 2009; Rieger et al., 2020b). Educators who use ABP may encounter resistance at the organizational level, citing concern about an already crowded curriculum (Casey, 2009). Moreover, health researchers using arts-based methods can expect their work to "exist at the margins of many disciplines" (Cox et al., 2010, p. 120), which is not always a supportive place to be.

\section{Implications for Educators}

The importance of diverse teaching and learning approaches cannot be underestimated (Rieger \& Chernomas, 2013), and the wise teacher makes sure that creativity is given a place of importance. While ABP holds great potential for engaging students in their learning, we believe this approach has been limitedly taken up within nursing education. Findings from our study illustrate that a $\mathrm{CwABP}$ approach to a self-care assignment was generally well received among nursing students and allowed for creative ways of exploring stressors experienced in class and clinical practice. Participants identified that engaging in creative expression was itself a form of self-care, suggesting that integration of $\mathrm{CwABP}$ into nursing coursework may support students in reducing stress and promoting well-being.

Nursing student perspectives on a creative self-care assignment as presented in this article illustrate that giving students curricular time to reflect on their stressors and to engage in self-care is one way to open space for acknowledgement of the stressors that they experience. We believe it is one important step towards meeting our obligation to prepare students for their professional role in clinical practice. Furthermore, it is imperative for nurse educators and leaders not only to encourage students to identify their personal stressors but also to look inside their own institution to consider the structural and organizational contexts that may create further stressors for students or make it difficult for them to manage those they already experience (Jenkins et al., 2019).

Ensuring substantive learning through $\mathrm{ABP}$ and appropriate evaluation of creative assignments is a priority for students and educators alike (Lodge \& Bonsanquet, 2014). It is also important to connect creative learning activities with relevant course outcomes (Oermann, 2015). For our project, linking the self-care assignment to core course concepts was imperative because it allowed students to more clearly understand the assignment's purpose and enhance their capacity to see important benefits of engaging in both self-care and a $\mathrm{CwABP}$ project.

Yet while participants in our study expressed that the CwABP assignment supported learning about both self-care practices and core course concepts such as fitness to practise and 
personal well-being, evaluation of assignments was identified as detracting from the CwABP experience. Specifically, participants expressed perceptions of unfairness in evaluation of the assignments, suggesting that further examination of evaluative procedures may be warranted. As stated by Smith (2017), "The objective evaluation of creative work is likely a challenge faced by teachers around the world, in a variety of pedagogical areas" (p. 26). Indeed, grading an ABP assignment does raise issues for nursing educators, and while it is unlikely that artwork can be assessed objectively, it is key that educators be as value-free as possible when evaluating students' creative projects (Gentile \& Murnyack, 1989). Perceiving students' creativity as a strength (Slaughter et al., 2018) is an important first step in this process.

Rubrics offer one way to assess work as objectively as possible and to communicate expectations clearly to students (Smith, 2017). Haugnes and Russell (2016) linked faculty members' resistance to grading works of art to their belief that grading and the use of rubrics would stifle students' creative expression. However, these authors make a strong case for teachers to thoughtfully incorporate rubrics to lessen the uneasy relationship between artistic creations and standardized academic assessment practices. Findings from a survey conducted by Haugnes and Russell (2016) revealed that "most instructors and students perceive rubrics to have a neutral or positive effect on student creativity" (Results section, para. 3). They further suggested that rubrics, "if offered in a spirit of communication, access, and transparency, will not destroy students' creativity. Done right, they may even enhance it" (Conclusion, para. 3).

From our perspective as educators, the challenges associated with offering students a choice in assignment format resulted in inequities that were both unintended and unexpected. Shifting the requirement for all students to complete both a creative and a textual component for the assignment did not necessarily resolve the issue; students may still perceive that personal experiences or artistic expression are being evaluated. It would be wise to ensure that assignments within a course take the same form, with all students completing a creative project, a textual paper, or a combined version. Philosophically, educators should explore whether such an assignment could be evaluated with a participation grade to avoid perceptions of unfairness or evaluation of creative expression. Although this approach of "no grade" evaluation may support the needs of some students, it may unwittingly disadvantage students who do exceptional work yet receive the same grade as their peers whose work may be less strong (see Schinske and Tanner, 2014, for a thoughtful analysis of grading less or differently). Alternatively, educators may simply evaluate how the criteria are met within the integration of the textual and creative components and avoid grading the quality of the creative endeavour itself. When taking this approach, it is worth carefully considering the development of criteria that could be used and ensuring these criteria are transparent and communicated effectively to students (Smith, 2017). Regardless of which approach educators take, we have learned to be cautious about how to grade the creative component of the assignment to avoid the perception that personal self-care or creative expressions are being graded. However, as advised by Gentile and Murnyack (1989), "if art education is to be taken seriously, it must be graded seriously" (p. 41), and the use of "agreed-upon evaluative standards could contribute to the trustworthiness and legitimacy of the arts-based academic project" (Slaughter et al., 2018, Discussion section, para. 6).

\section{Conclusions}

Integrating self-care into nursing education is highly beneficial for supporting students in coping with general student stressors and, in particular, those associated with clinical practice. While self-care may not be the answer for every type of encountered stressor, it can enhance fitness 
to practice, support students' well-being, and invite habituation of a practice that will be necessary for students to engage in throughout their professional lives (Blum, 2014; Canadian Nursing Students' Association, 2009). Through our analysis of students' qualitative responses to a creative self-care assignment, we identified that a CwABP approach is a successful and generally well received way to weave self-care into a nursing curriculum. However, it will serve educators well to consider the challenges of grading creative ABP assignments and ensure that guidelines are clear and transparent so that students are aware of what is and what is not graded within the assignment. It is also important to be cognizant of how vulnerability may assert itself for students when completing this assignment and to be critically aware of the systemic processes that may create stress for students or present barriers for them to address stressors they experience. Alongside this critical awareness, educators must ensure that there are effective and accessible structural supports in place for students' mental health. Although we have emphasized some cautions to consider when using an assignment such as the one described in this paper, we wholeheartedly recommend its use. We further believe that educators should complete the assignment themselves so that they can embody the criteria in ways that will allow them to support the process for students. Creating criteria for an assignment as an intellectual endeavour is quite different from engaging in completing the assignment. The latter should strengthen the clarity of assignment design and ensure that assignment expectations are realistic and clear. Educators can look forward to an interesting grading experience when they introduce a creative arts-based assignment. 


\section{References}

Acharya, L., Jin, L., \& Collins, W. (2018). College life is stressful today-Emerging stressors and depressive symptoms in college students. Journal of American College Health, 66(7), 655-664. https://doi.org/10.1080/07448481.2018.1451869

BC College of Nurses and Midwives. (2018). Professional standards for registered nurses and nurse practitioners. https://www.bccnp.ca/Standards/RN_NP/ProfessionalStandards/Pages/Default.aspx

Blum, C. (2014). Practicing self-care for nurses: A nursing program initiative. The Online Journal of Issues in Nursing, 19(3), 3. https://doi.org/10.3912/OJIN.Vol19No03Man03

Braun, V., \& Clarke, V. (2006). Using thematic analysis in psychology. Qualitative Research in Psychology, 3(2), 77-101.

Braun, V., \& Clarke, V. (2019). Reflecting on reflexive thematic analysis. Qualitative Research in Sport, Exercise and Health, 11(4), 589-597. https://doi.org/10.1080/2159676X.2019.1628806

Braun, V., Clarke, V., Terry, G., \& Hayfield, N. (2019). Thematic analysis. In P. Liamputtong (Ed.), Handbook of research methods in health and social sciences (pp. 843-860). Springer.

Canadian Nursing Students' Association. (2009). Self-care practices among nursing students. http://cnsa.ca/self-care-practices-among-nursing-students/

Casey, B. (2009). Arts-based inquiry in nursing education. Contemporary Nurse: A Journal for the Australian Nursing Profession, 32(1-2), 69-82.

Chinn, P. (1994). Developing a method for aesthetic knowing in nursing. In P. Chinn \& J. Watson (Eds.), Art and aesthetics in nursing (pp. 19-40). League for Nursing Press.

Cox, S. M., Lafrenière, D., Brett-MacLean, P., Collie, K., Cooley, N., Dunbrack, J., \& Frager, G. (2010). Tipping the iceberg? The state of arts and health in Canada. Arts \& Health, 2(2), $109-124$.

Darbyshire, P. (1994). Understanding caring through arts and humanities: A medical/nursing humanities approach to promoting alternative experiences of thinking and learning. Journal of Advanced Nursing, 19(5), 856-863.

Duhamel, K. (2016). Bringing us back to our creative senses: Fostering creativity in graduatelevel nursing education: A literary review. Nurse Education Today, 45, 51-54. https://doi.org/10.1016/j.nedt.2016.06.016

Elhammoumi, C., \& Kellam, B. (2017). Art images in holistic nursing education. Religions, 8(6), 103. https://doi.org/10.3390/rel8060103

Emmanuel, E. (2016). Creative art: A means of seeing for learning. Australian Nursing \& Midwifery Journal, 23(11), 46.

Fischer, M., \& Kiernan, M. (2019). Student nurses' lived experience of patient safety and raising concerns. Nurse Education Today, 77, 1-5.

Gentile, J. R., \& Murnyack, N. C. (1989). How shall students be graded in discipline-based art education? Art Education, 42(6), 33-41. 
Haugnes, N., \& Russell, J. L. (2016). Don't box me in: Rubrics for artists and designers. To Improve the Academy, 35(2), 249-283.

Jenkins, E., Slemon, A., O’Flynn Magee, K., \& Mahy, J. (2019). Exploring the implications of a self-care assignment to foster undergraduate nursing student mental health: Findings from a survey research study. Nurse Education Today, 81, 13-18.

Lodge, J. M., \& Bonsanquet, A. (2014). Evaluating quality learning in higher education: Reexamining the evidence. Quality in Higher Education, 20(1), 3-23.

Lutter, S., Pucino, C., \& Jarecke, J. (2018). Arts-based learning strategies in clinical postconference: A qualitative study. Journal of Nursing Education, 57(9) 549-553. https://doi.org/10.3928/01484834-20180815-07

MacDonnell, J., \& Macdonald, G. (2011). Arts-based critical inquiry in nursing and interdisciplinary professional education: Guided imagery, images, narratives, and poetry. Journal of Transformative Education, 9(4), 203-221. https://doi.org/10.1177/1541344612441083

McGarry, J., \& Aubeeluck, A. (2013). A different drum: An arts-based educational program. Nursing Science Quarterly, 26(3) 267-273. https://doi.org/10.1177/0894318413489200

Milligan, F., Wareing, M., Preston-Shoot, M., Pappas, Y., Randhawa, G., \& Bandol, J. (2017). Supporting nursing, midwifery and allied health professional students to raise concerns with the quality of care: A review of the research literature. Nurse Education Today, 57, 29-39. https://doi.org/10.1016/j.next.2017.06.006

Nguyen, M., Miranda, J., Lapum, J., \& Donald, F. (2016). Arts-based learning: A new approach to nursing education using andragogy. Journal of Nursing Education, 55(7), 407-410.

Oermann, M. (2015). Technology and teaching innovations in nursing education: Engaging the student. Nurse Educator, 40(2), 55-56. https://doi.org/10.1097/NNE.0000000000000139

Pavill, B. (2011). Fostering creativity in nursing students: a blending of nursing and the arts. Holistic Nursing Practice, 25(1), 17-25.

Purnell, M. (2016). Art, aesthetics, and stories: Communicating value and meaning in nursing. Beginnings: American Holistic Nursing Association, 36(1), 14-16.

Rieger, K. L., \& Chernomas, W. M. (2013). Arts-based learning: Analysis of the concept for nursing education. International Journal of Nursing Education Scholarship, 10, 1-10. https://doi.org/10.1515/ijnes-2012-0034

Rieger, K. L., Chernomas, W. M., McMillan, D. E., \& Morin, F. L. (2020a). The arts as a catalyst for learning with undergraduate nursing students: findings from a constructivist grounded theory study. Arts \& Health, 12(3), 250-269. https://doi.org/10.1080/17533015.2019.1608569

Rieger, K. L., Chernomas, W. M., McMillan, D. E., \& Morin, F. L. (2020b). Navigating creativity within arts-based pedagogy: Implications of a constructivist grounded theory study. Nurse Education Today, 91, 104465.

Robinson, Sir K. (2006). Do schools kill creativity? [Video]. TED Conferences. https://www.ted.com/talks/sir_ken_robinson_do_schools_kill_creativity? 
Robinson, Sir K. (2017). Out of our minds: The power of being creative (3rd ed.). Wiley and Sons.

Rodney, P., Kadyschuk, S., Liaschenko, J., Brown, H., \& Musto, L. (2013). Moral agency: Relational connections and support. In J. L. Storch, P. Rodney, \& R. Starzomski (Eds.), Toward a moral horizon: Nursing ethics for leadership and practice (2nd ed.). Pearson Education Canada.

Rolfe, G. (2014). Editorial: Educating the good for nothing student. Journal of Clinical Nursing, 23, 1459-1460. https://doi.org/10.1111/jocn.1255

Schinske, J., \& Tanner, K. (2014). Teaching more by grading less (or differently). CBE—Life Sciences Education, 13(2), 159-166. https://doi.org/10.1187/cbe.CBE-14-03-0054

Seaward, B. L. (2018). Managing stress: Principles and strategies for health and well-being (9th ed.). Jones and Bartlett Publishers.

Sinclair, J., Papps, E., \& Marshall, B. (2016). Nursing students' experiences of ethical issues in clinical practice: A New Zealand study. Nursing Education in Practice, 17, 1-7. https://doi.org/10.1016/j.nepr.2016.01.005

Slaughter, S. E., Archibald, M. M., Albrecht, L., Say, B., Paul, P., \& Scott, S. D. (2018). Valuing arts-based academic projects in a faculty of nursing: Experiences of graduate students and supervisors. Quality Advancement in Nursing Education, 4(1), Article 6. https://doi.org/10.17483/2368-6669.1126

Smith, J. S. (2017). Assessing creativity: Creating a rubric to effectively evaluate mediated digital portfolios. Journalism \& Mass Communication Educator, 72(1), 24-36.

Wrench, A., Garrett, R., \& King, S. (2013). Guessing where the goal posts are: Managing health and well-being during the transition to university studies. Journal of Youth Studies, 16(6), 730-746, https://doi.org/10.1080/13676261.2012.744814 